\title{
A Multilevel Analysis of the Impact of Socio-Structural and Environmental Influences on Condom Use Among Female Sex Workers
}

\author{
Alfonso Ang • Donald E. Morisky
}

Published online: 23 March 2011

(C) The Author(s) 2011. This article is published with open access at Springerlink.com

\begin{abstract}
This study uses multilevel analysis to examine individual, organizational and community levels of influence on condom use among female commercial sex workers (FSW) in the Philippines. A randomized controlled study involving 1,382 female commercial sex workers assigned to three intervention groups consisting of peer education, managerial training, combined peer and managerial intervention and a usual care control group was conducted. The results of the multilevel analysis show that FSWs who work in establishments with condom use rules tend to have a higher level of condom use $(\beta=.70$, $P<0.01)$. Among the different intervention groups, the combined peer and managerial intervention had the largest effect on condom use $(\beta=1.30, P<0.01)$ compared with the usual care group. Using a three-level hierarchical model, we found that $62 \%$ of the variation lies within individuals, whereas $24 \%$ and $14 \%$ of the variation lies between establishments, and communities, respectively. Standard errors were underestimated when clustering of the FSWs in the different establishments and communities were not taken into consideration. The results demonstrate the importance of using multilevel analysis for communitybased HIV/AIDS intervention programs to examine individual, establishment and community effects.
\end{abstract}

\footnotetext{
A. Ang

Department of General Internal Medicine, UCLA School

of Medicine, Westwood, CA 90024, USA

D. E. Morisky

UCLA School of Public Health, UCLA, 650 Charles E. Young

Dr. South, Los Angeles, CA 90095-1772, USA
}

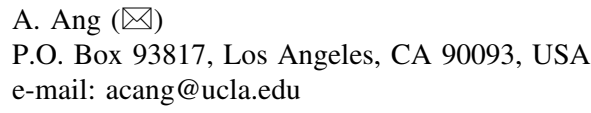

Keywords Condom use - HIV/AIDS - STD .

Commercial sex workers · Sexual behavior

\section{Introduction}

The concept of improving HIV/STI prevention through community-based research has gained popularity among health promotion workers [1-4]. Often researchers are not only interested in personal factors that contribute to HIV/ STI risk reduction, but are also interested in integrating situational and environmental factors [5, 6] that can help explain HIV risk reduction in the broader context of community HIV/STI health risk reduction [7-10].

The rationale behind community-based prevention is that the individual's attitudes and behaviors are often influenced by the social contexts to which the individuals belong [11-13]. Community-based HIV/STI prevention efforts therefore often focus on the various levels within the community that influence risk behaviors, including individual, organizational and community influences. For example, in examining commercial sex work establishments, condom use outcomes are only partly the result of individual factors such as self-efficacy and motivation to use condoms. Condom use outcomes are also influenced by factors such as the individual establishment's condom use policy, and whether the establishment makes condoms available. Hence, individuals with similar levels of condom use motivation may exhibit different levels of condom use behavior at different establishments [14-18]. Thus, a multilevel analysis, whereby the effects at the individual level are examined in conjunction with the sex establishment level can provide us with a more complete picture and give us a better understanding of the context in which the process of change is taking place. This type of 
systematic analysis can also help HIV/STI prevention scientists formulate a more effective and comprehensive prevention program, whereby change is not only targeted at the individual level, but also at the socio-structural levels, allowing for possible long term structural change and effective policy making within the organization.

Despite the growing interest in multilevel analysis [5, 13, 20, 21], there are gaps in the literature concerning community-based research on HIV/STI prevention. First, the literature is quite limited in investigating HIV/STI transmission at both individual, sex establishment and community levels simultaneously. Second, there is a limited understanding of personal influences on condom use and how these personal influences relate to socio-structural and community influences. Third, community-based intervention are sometimes administered at the city or community level, and there is a need to partition out the variation of the effects into the corresponding person-level, sex establishment-level and community-level effects, in order to provide us with a better understanding of implementation effects of the intervention at the various establishments within the different communities.

Different conclusions may also be reached when researchers fail to consider the different levels within the data [22-24], since the observations collected may lack independence due to the nested structure of the data. Methods for assessing multilevel data [22, 23, 25] make it possible to partition individual, establishment and community level effects, thereby allowing researchers to obtain more precise measures of standard errors, resulting in more accurate analysis that takes into account the nested structure of the data.

The purpose of this study is to use a multilevel approach to examine individual, establishment and community level effects in a large community-based HIV/AIDS/STI intervention prevention program. Previous research had examined 897 women who worked in entertainment establishments in the Philippines [6]. The primary outcome of the previous study was condom use as a binary "yes/no" variable based on the last time these women had sex with a customer. This study extends the research by examining how often they use condoms based on a previously validated three item condom use scale[7], and also uses a larger recently updated data sample of $n=1382$. We also used a three-level hierarchical model to examine the effects at the person, establishment and community levels, and demonstrate that standard errors may sometimes be underestimated if the community-level is not taken into account for a community-based intervention study.

Commercial sex work is not legal in the Philippines, however women who work in entertainment establishments are required to register at their local Social Hygiene Clinic (SHC) and receive weekly or bi-monthly checkups. These women, commonly referred to as guest relations officers (GROs) are employed in bars, nightclubs, disco houses, karaoke TV centers and massage parlors [19]. These GROs are often referred to as indirect sex workers, as opposed to the brothel-based or freelance, direct female sex workers. The establishment where the GROs are employed serves as the situational context for condom use practices for the GROs. Previous research identified establishment policies as an important factor influencing condom use among GROs [26-29]. These findings support the position that the establishments provide an important situational context for condom use among GROs, and are an important component for changing risk behavior.

Previous interventions with establishments (brothels) in Indonesia and Thailand have led to increased condom use among GROs [28, 29]. In Thailand, the Ministry of Public Health established programs, including promotion of condom use during commercial sex, and health education to prevent HIV transmission. This resulted in a broader government initiated community policy of $100 \%$ condom use for preventing the spread of HIV infection. As a consequence, there were significant increases in condom use among female sex workers and their male clients [28, 31]. Clearly, the establishments and the communities where the GROs work exert vital influence on condom use. The analysis of HIV/STI interventions involving this type of data should incorporate the analysis of effects at the establishment and at the community level.

\section{The Data}

The data used in this research is based on a large-scale study using a community participatory research approach [2, 6, 32]. Female GROs $(N=1382)$ were recruited from four different cities in the southern Philippines and were selected as participants in a large community-based HIV/ STI education and prevention program [6, 19]. These GROs work in over 100 different commercial sex establishments. The overall participation rate was $98.5 \%$, with very few GROs refusing to participate in the study. Establishments included in the study consist of bars, nightclubs, karaoke TV, disco clubs, and massage parlors. The average age of the GROs was 23.5 years, and their age ranged from 15 to 54 . At the time of the baseline assessment, the participants had worked an average of 12.66 months $(\mathrm{SD}=10.82)$ and had an average of 9.07 years of education. Only $11.31 \%$ of the sample was married with $54.4 \%$ of the participants reporting having at least one child. In the study, there were 103 establishments within which the women were clustered. These clusters ranged in size from 2 to 47 . The average size was 9 women 
per cluster. The four participating cities were randomly assigned to one of the intervention groups (peer education, managerial training, or the combination of peer education and managerial training.)

\section{Methods}

\section{Intervention Description}

An assessment of HIV/AIDS-related knowledge, attitudes and practices were conducted in each of the intervention and control cities by trained interviewers. The questionnaires were translated to the local dialect, and subsequently back translated, with back translation receiving a 99\% level of concordance. The questionnaires were pre-tested on GROs in a neighboring province. Based on the results of the pretest, a modified version of the questionnaire was developed and administered at baseline. Baseline assessments consisted of items covering the areas of demographics, knowledge, attitudes, beliefs, behaviors, and selfefficacy for condom use. The intervention cities were randomly assigned into one of three intervention groups. The first group was the peer education intervention group and this group received a special intervention consisting of peer leader training, small group discussions, role playing for development of social and self-regulative skills, guided practice of communication and negotiating skills, and establishment and reinforcement of group norms concerning safer sexual practices. The second group consisted of managers of the establishments employing the GROs. This group participated in training and focus group discussions to identify mechanisms that will facilitate the introduction of AIDS education and prevention policies, including condom promotion in the establishment. The third intervention group received both peer education and managerial training intervention. The control group received usual educational materials and presentations by the social hygiene clinic nurse. Assessments of the intervention effects were made 12 months after the intervention.

\section{Measures}

An interview survey was used to measure knowledge of HIV/AIDS, attitudes and self-efficacy on condom use in reference to their work practices with clients among the GROs. Preliminary exploratory analyses with varimax rotation were conducted on these measures. All Items used in each measure loaded at .70 or higher in the exploratory factor analyses. Alpha reliabilities of all measures were also examined and will be presented in the following paragraphs.

\section{Aids Knowledge Index}

The knowledge index items consisted of a series of 10 true or false questions about the methods of HIV/AIDS transmission such as blood transfusions, sexual intercourse, kissing, drug use, etc. The content validity of this knowledge index measure (knowledge score ranges from 0 to 10) had been established by an expert panel of AIDS researchers in the Philippines.

\section{Attitude Towards Condom Use}

Attitude towards condom use was measured by a 10 -item, 5 -point scale measure. These items included scaled questions ranging from 1 (never) to 5 (always) that consists of items like "condoms are easy to use", "the price of condoms is too high to use regularly", "condoms cause pain or discomfort", etc. The Cronbach's alpha reliability coefficient for the attitude measure was 0.88 . The range of possible scores for the attitude to condom use measure is from 5 to 50 .

\section{Self-Efficacy Measure}

Self-efficacy to condom use was measured by the 6-item perceived self-efficacy to condom use scale [33]. Responses to these items were made on a five-point scale from strongly agree (1) to strongly disagree (5). The range of possible scores for the self-efficacy scale is from 6 to 30 .

\section{Condom Use Measure}

Condom use is the main outcome variable of interest, and was assessed with 3 questions. This measure included scaled questions ranging from 0 (never) to 4 (always) that asked GROs- - How often they use a condom with vaginal sex; How often they suggest using condoms to clients; And how often they carry a condom with them at work. The Cronbach's alpha reliability coefficient for the self-efficacy scale was 0.81 . The range of possible scores for the condom use scale is from 0 to 12 .

\section{Establishment Rule}

At the establishment level, the variable establishment rule was coded $1=$ yes, $0=$ no, indicating whether the establishment had a policy that required GROs to use condoms every time they engage in risky sexual behavior.

\section{Intervention Status Indicators}

At the community level, the different cities were dummycoded depending on the type of intervention that was 
administered in each city (i.e., peer education, managerial training, combined peer and managerial training, and usual care or control group.) In the analysis, the usual care or control group is the reference group for comparison.

\section{Statistical Analysis}

Since the scope of this research involved the participation of the GROs in the different work establishments, located in different cities or communities within the intervention study, a methodology involving multilevel analysis that examined of how condom use can be affected by sociostructural and environmental influences, as well as the effects of a mandatory condom use policy on self-reported condom use behavior was implemented. More specifically, in order to account for the nesting of the GROs in the different establishments, and the nesting of establishments in the different cities, a multilevel approach using a threelevel hierarchical model was used. During the intervention, all individuals were selected to participate within each establishment. The structure of the study design results in autocorrelation of individuals within establishments, and would violate the assumption of independence for ordinary least squares regression (OLS) analyses. This may have the effect of underestimating standard errors and increasing Type I error rates. This underestimation of standard errors will be examined in the analyses by comparing the results for the OLS regression with the hierarchical linear models, where the nesting of individuals in establishments, and establishments in cities or communities are taken into consideration. HLM 6 for Windows was the software used to estimate the three-level hierarchical linear models [22].

In using three-level hierarchical models, the effects were analyzed simultaneously at three-levels of aggregationthe individual level, establishment level and the community level. In the level-1 or individual level model, condom use was modeled as a function of the GRO's personal characteristics, such as knowledge, attitude, and self-efficacy. A level-1 random effect was added to capture the variation within the individual GROs.

In the level-2 or establishment level model, the levelone personal characteristics were modeled as a function of establishment rule, where establishment rule is dummy coded, with establishment rule coded as 1 indicating that the GRO works in an establishment with a mandatory condom use rule, and establishment rule coded as 0 , signifying that the GRO works in an establishment with no condom use rule. A level-2 random effect was added to capture the variation between establishments.

In the level-3 or community-level model, the level-2 variables were modeled as a function of the intervention, where the intervention effects were dummy-coded depending on the city and type of intervention that the GRO belonged to. We also examined cross-level interactions, which are conventional interactions (cross-product terms) between establishment-level and community-level factors. Specifically, we look at the interaction between establishment rule and the three types of interventions (i.e., establishment rule $\times$ peer group, establishment rule $\times$ managerial group, and establishment rule $\times$ combined group). A third level random effect was included in the model, to capture the variation across the different intervention cities.

\section{Results}

All the variables were initially analyzed descriptively by univariate statistics, including examining frequencies, percentages, means and standard deviations. The data were examined for the presence of missing values, influential outliers, skewness and kurtosis for key continuous predictor variables. Missing information was imputed using multivariate imputation by chained equation method [34].

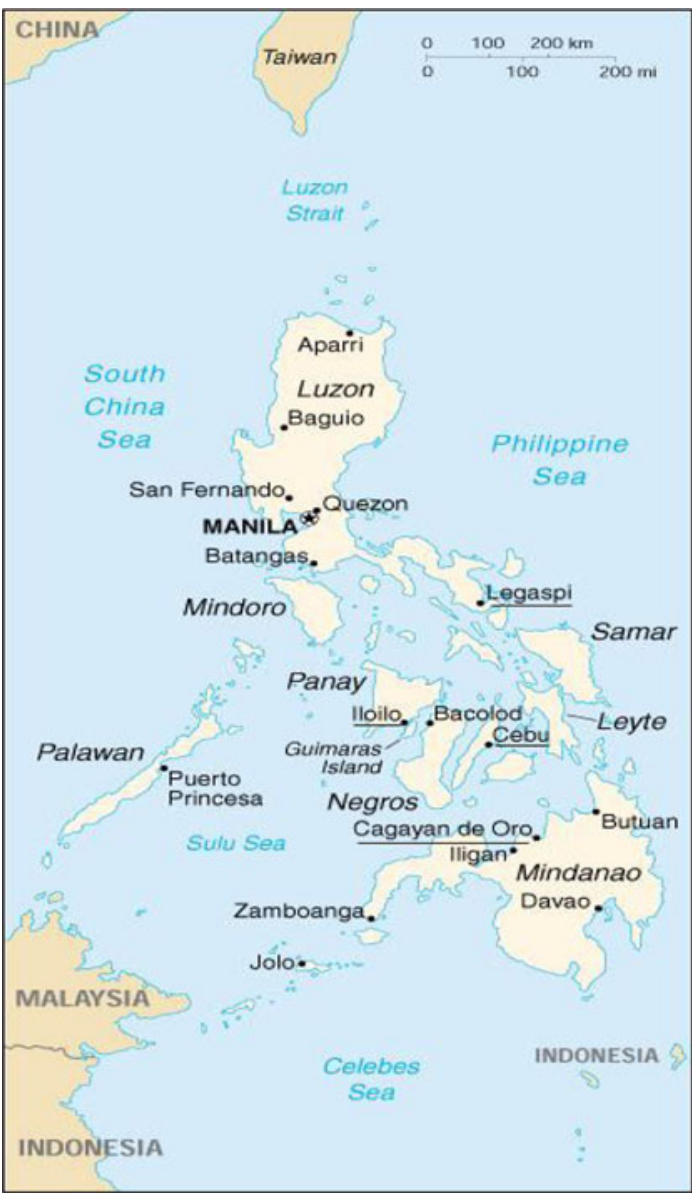

Fig. 1 Map of the Philippines showing the geographic location of the intervention sites (underlined cities) 
Table 1 Demographic characteristics of GROs at baseline by intervention and control cities

\begin{tabular}{|c|c|c|c|c|}
\hline & Legaspi $\left(\mathrm{E}_{1}\right)(n=255)$ & Cagayan de Oro $\left(E_{2}\right)(n=459)$ & Cebu $\left(E_{3}\right)(n=398)$ & Ilo-Ilo (C) $(n=270)$ \\
\hline \multicolumn{5}{|l|}{ Age (years) } \\
\hline Mean & 23.23 & 23.62 & 22.63 & 24.70 \\
\hline SD (Min., Max.) & $5.14(15,41)$ & $5.20(10,48)$ & $4.92(15,39)$ & $7.11(14,54)$ \\
\hline \multicolumn{5}{|l|}{ Years of schooling (years) } \\
\hline Mean & 8.61 & 9.63 & 8.88 & 8.72 \\
\hline SD (Min., Max.) & $2.21(2,14)$ & $2.13(1,14)$ & $2.16(2,14)$ & $2.13(1,14)$ \\
\hline \multicolumn{5}{|l|}{ Average weekly income (pesos) } \\
\hline Mean & 1045 & 1223 & 1278 & 1480 \\
\hline SD (Min., Max.) & $797(100,8000)$ & $988(150,9000)$ & $1132(50,8000)$ & $1500(100,9000)$ \\
\hline \multicolumn{5}{|l|}{ Marital status } \\
\hline Single, never married (\%) & 62 & 45 & 62 & 48 \\
\hline Single, lives with boyfriend (\%) & 30 & 25 & 18 & 24 \\
\hline Separated, living alone $(\%)$ & 5 & 11 & 10 & 19 \\
\hline Married (\%) & 2 & 17 & 8 & 9 \\
\hline Widowed (\%) & 1 & 2 & 2 & 0 \\
\hline
\end{tabular}

$E_{1}$ peer education, $E_{2}$ manager/supervisor training \& educational policy, $E_{3}$ combination $\mathrm{E}_{1}$ and $\mathrm{E}_{2}, C$ control group (usual care)

A breakdown of the demographic characteristics of the GROs based on the intervention and control cities (see Fig. 1) at baseline is shown in Table 1. The socio-economic backgrounds of the GROs were generally similar among the four cities, with some slight variations. Iloilo GROs were slightly older, with an average age of 24.7 years, compared to GROs from Legaspi $(t=3.2$, $P<.05)$, Cagayan de Oro $(t=3.1, P<.05)$, and Cebu City $(t=3.6, P<.001)$. Iloilo GROs also earned slightly more relative to the other cities $(1,480$ Pesos, $t=3.6$, $P<.05 ;$ At the time of the study, $\$ 1=24.50$ Pesos). Cagayan de Oros' GROs were slightly more educated (9.63 years of education) compared to GROs from Legaspi $(t=2.8, P<.05)$, Cebu $(t=2.5, P<.05)$, and Iloi-ilo $(t=2.6, P<.05)$. A significantly higher percentage of Cagayan de Oros' GROs were married $\left(16.8 \%, \chi^{2}=30.5\right.$, $P<.05)$, compared to the other cities. Legaspi City had the lowest percentage of married GROs $\left(2.4 \%, \chi^{2}=21.3\right.$, $P<.05)$.

Preliminary analysis of the data consists of examining the change in knowledge, attitude and condom use behavior from pretest to post-test. As illustrated in Table 2, there were significant increases in knowledge on HIV/ AIDS transmission from baseline to post-test for the intervention groups, and no significant change in knowledge for the control group $(t=1.1, P=.92)$. Baseline to post-test change in attitude on condom use also increased significantly for all the intervention groups but did not change significantly for the control group. There was also a significant increase in condom use for the intervention groups and not for the control group. These preliminary results show the overall effects of the intervention at the unadjusted aggregate level without controlling for individual, establishment and community variables.

\section{Multilevel Analysis}

The next phase in the analysis consists of a more detailed analysis, using the three-level hierarchical models to analyze the data at the different levels. The condom use outcome was normally distributed, and we estimated the threelevel hierarchical linear model using restricted maximum likelihood (REML) that assumes multivariate normality for the model residuals. In all the models, continuous predictors were mean-centered, including age, years in education, knowledge index, condom use attitude and self-efficacy measures.

\section{GRO-Level Analysis}

Based on the findings of the study, it was found that the GROs' knowledge on HIV/AIDS had a significant effect on condom use $(\beta=.064, P<.05)$. GROs that had higher knowledge concerning the transmissibility of HIV/AIDS tend to use condoms more often. There was also a significant effect of attitude on condom use-the more positive the attitude towards condom use, the higher the level of condom use $(\beta=.062, P<.01)$.

\section{Establishment-Level Analysis}

Among all the establishments surveyed, $46.6 \%$ of the establishments had a policy of mandatory condom use when engaging in sex with customers. The results of the 
Table 2 Comparison of knowledge, attitudes and condom use between control and intervention groups

\begin{tabular}{|c|c|c|c|}
\hline Survey measures & Baseline & Post test (SD) & $t$-value \\
\hline \multicolumn{4}{|l|}{ Knowledge score (ranges from 0 to 10 ) } \\
\hline Peer education & $4.16(1.01)$ & $6.22(1.16)$ & $4.4 * *$ \\
\hline Managerial training & $4.25(1.17)$ & $6.35(1.12)$ & $4.5^{* *}$ \\
\hline Combined (peer + managerial) group & $4.29(1.08)$ & $6.48(1.01)$ & $4.8 * *$ \\
\hline Control group & $4.16(1.30)$ & $4.75(1.31)$ & 1.1 \\
\hline \multicolumn{4}{|c|}{ Attitudes towards condoms score (ranges from 5 to 50 ) } \\
\hline Peer education & $42.71(1.29)$ & $46.21(1.34)$ & $3.1 * *$ \\
\hline Managerial training & $44.56(1.29)$ & $48.54(1.33)$ & $3.8 * *$ \\
\hline Combined (peer + managerial) group & $43.79(1.25)$ & $48.75(1.24)$ & $3.9 * *$ \\
\hline Control group & $45.19(1.30)$ & $44.92(1.25)$ & .94 \\
\hline \multicolumn{4}{|l|}{ Self efficacy score (ranges from 6 to 30 ) } \\
\hline Peer education & 17.11(1.13) & $18.23(1.13)$ & $2.2 *$ \\
\hline Managerial training & $17.36(1.19)$ & $18.38(1.18)$ & $2.1^{*}$ \\
\hline Combined (peer + managerial) group & $17.11(1.11)$ & $18.47(1.22)$ & $2.4^{*}$ \\
\hline Control group & $17.27(1.31)$ & $17.91(1.13)$ & .98 \\
\hline \multicolumn{4}{|l|}{ Condom use score (ranges from 0 to 12 ) } \\
\hline Peer education & $6.56(1.26)$ & $7.33(1.17)$ & $3.1 * *$ \\
\hline Managerial training & $6.52(1.20)$ & $7.59(1.04)$ & $3.3 * *$ \\
\hline Combined (peer + managerial) group & $6.48(1.22)$ & $8.15(1.12)$ & $3.7 * *$ \\
\hline Control group & $6.62(1.27)$ & $6.21(0.94)$ & .92 \\
\hline
\end{tabular}

$* P<0.05$

** $P<0.001$

Table 3 Multilevel analysis of condom use-OLS regression vs. hierarchical linear model results

\begin{tabular}{|c|c|c|c|c|c|c|}
\hline Fixed effects ${ }^{a}$ & $\begin{array}{l}\text { OLS estimate } \\
\text { (cluster effect ignored) }\end{array}$ & S.E. (OLS) & $t$-value & $\begin{array}{l}\text { Hierarchical linear } \\
\text { model estimate }\end{array}$ & S.E. (HLM) & $t$-value \\
\hline \multicolumn{7}{|l|}{ Individual-level } \\
\hline Knowledge & 0.063 & 0.019 & $3.32 * *$ & 0.064 & 0.026 & $2.46^{*}$ \\
\hline Attitude & 0.061 & 0.012 & $5.08 * *$ & 0.062 & 0.018 & $3.44 * *$ \\
\hline Self-efficacy & 0.051 & 0.017 & $3.00^{* *}$ & 0.05 & 0.030 & 1.67 \\
\hline \multicolumn{7}{|l|}{ Establishment-level } \\
\hline Establishment rule & 0.704 & 0.113 & $6.23 * *$ & 0.705 & 0.128 & $5.51 * *$ \\
\hline \multicolumn{7}{|l|}{ City-level } \\
\hline Peer education & 0.251 & 0.098 & $2.56^{* *}$ & 0.250 & 0.110 & $2.27 *$ \\
\hline Managerial training & 0.628 & 0.158 & $3.97 * *$ & 0.628 & 0.264 & $2.38 * *$ \\
\hline Combined & 1.306 & 0.098 & $13.33 * *$ & 1.304 & 0.278 & $4.69 * *$ \\
\hline \multicolumn{7}{|l|}{ Cross-level interaction } \\
\hline Peer $\times$ establishment rule & 0.421 & 0.124 & $3.40 * *$ & 0.421 & .147 & $2.86^{* *}$ \\
\hline Managerial $\times$ estab. rule & 0.563 & 0.176 & $3.20 * *$ & 0.563 & .209 & $2.69 * *$ \\
\hline Combined $\times$ estab. rule & 0.840 & 0.238 & $3.53 * *$ & 0.840 & .325 & $2.58 * *$ \\
\hline
\end{tabular}

Estimation of variance components for hierarchical models

Variation between GROs

Variation between establishments

Variation between cities

$0.79($ S.E. $=0.063) * *$
$0.31($ S.E. $=0.069) * *$
$0.18(\text { S.E. }=0.031)^{* *}$

${ }^{a}$ Model also controlled for age, education and marital status and baseline condom use

* $P<0.05$

** $P<0.01$ 
establishment level analysis in Table 3 shows that mandatory condom use was significant $(\beta=.705, P<0.01)$. GROs that worked in an establishment with a mandatory condom use rule had a higher level of condom use.

\section{Community-Level Analysis}

Among the different intervention groups, the combined peer and managerial intervention (Cebu City) had the largest main effect on condom use $(\beta=1.304, P<0.01)$ relative to the usual care group. The managerial intervention was also significant with the magnitude of the main effect at a slightly lower level than the combined peer and managerial intervention $(\beta=0.628, P<0.01)$. The peer intervention group also had a significant main effect on condom use compared to the usual care group $(\beta=0.25$, $P<0.05)$.

In examining the cross-level interaction effects, there was a significant cross-level interaction effect between peer intervention $\times$ establishment rule $(\beta=0.421, P<.01)$. Similarly, we found significant interaction effects between managerial intervention $\times$ establishment rule $(\beta=0.563$, $P<.01)$ and the combined intervention $\times$ establishment rule $(\beta=0.840, \quad P<.01)$. These interaction effects

Table 4 Effects of increased self-efficacy, knowledge, and attitude on condom use in establishments with a mandatory condom use policy vs. establishments with no condom use policy

\begin{tabular}{|c|c|c|c|}
\hline & $\begin{array}{l}\text { Establishments } \\
\text { with no condom } \\
\text { use policy }\end{array}$ & $\begin{array}{l}\text { Establishments } \\
\text { with condom } \\
\text { use policy }\end{array}$ & $\begin{array}{l}\% \\
\text { difference }\end{array}$ \\
\hline \multicolumn{4}{|c|}{ (1) Effect of a $10 \%$ increase in condom use knowledge } \\
\hline Control & 6.57 & 7.28 & 10.81 \\
\hline Peer & 6.82 & 7.95 & 16.57 \\
\hline Managerial & 7.19 & 8.46 & 17.66 \\
\hline $\begin{array}{l}\text { Combined } \\
\text { peer }+ \text { managerial }\end{array}$ & 7.87 & 9.42 & 19.70 \\
\hline \multicolumn{4}{|c|}{ (2) Effect of a $10 \%$ increase in condom use attitudes } \\
\hline Control & 6.82 & 7.52 & 10.26 \\
\hline Peer & 7.07 & 8.19 & 15.84 \\
\hline Managerial & 7.44 & 8.71 & 17.07 \\
\hline $\begin{array}{l}\text { Combined } \\
\text { peer }+ \text { managerial }\end{array}$ & 8.11 & 9.67 & 19.24 \\
\hline \multicolumn{4}{|c|}{ (3) Effect of a $10 \%$ increase in self-efficacy } \\
\hline Control & 6.63 & 7.34 & 10.71 \\
\hline Peer & 6.88 & 8.01 & 16.42 \\
\hline Managerial & 7.25 & 8.52 & 17.52 \\
\hline $\begin{array}{l}\text { Combined } \\
\text { peer }+ \text { managerial }\end{array}$ & 7.93 & 9.48 & 19.55 \\
\hline
\end{tabular}

Expected values were estimated from the hierarchical linear models, and computed separately for three scenarios. We assume a hypothetical increase of $10 \%$ in (1) knowledge, (2) attitudes and (3) selfefficacy indicate that participants who had the peer, managerial or combined interventions and at the same time worked in an establishment with the condom use rule had significantly higher condom use compared with intervention participants who worked in establishments with no condom use rule.

To illustrate this interaction effect, we estimated the expected values from the hierarchical linear models, and computed separately three scenarios assuming a hypothetical increase of $10 \%$ in (1) knowledge, (2) attitudes and (3) self-efficacy in Table 4. The results show an increase in condom use ranging in magnitude from 15.8 to $19.7 \%$ for the intervention groups when we compare establishments with condom use policy vs establishments without condom use policy. The difference in condom use for the control group in establishments with and without condom use policy were lower, and ranges from 10.3 to $10.8 \%$.

\section{Discussion of Results}

The results for the ordinary least squares regression (OLS) analysis (where clustering of the data is ignored) and the three-level hierarchical analysis are presented in Table 3. The estimates of the regression coefficients for the fixed effects are essentially the same for the OLS regression model and the three-level hierarchical models, however, the standard errors are underestimated in OLS regression where the clustering of the data is ignored. The estimates of the variance components for the three-level model indicate that there is substantial variation between GROs on condom use (0.79), as well as significant variation within establishments (0.31), and between the different intervention cities (0.18).

Self-efficacy was found to be significant in the OLS regression model where clustering of the data was ignored; however, this effect was not significant in the hierarchical model. The implication here is that standard errors are not correctly estimated when clustering of the GROs in the different establishments and intervention cities are not taken into consideration, leading us to a wrong conclusion.

The reason for this phenomenon is that there is a high degree of intra-class correlation in the between-establishment and between-city variances. The OLS analysis ignores the fact that a large proportion of the betweenestablishment variation lies between the different intervention cities. Intra-class correlation measures the proportion of the variance in the outcome that is between groups. This ratio, $\sigma^{2}$ between $/\left(\sigma^{2}\right.$ between $+\sigma^{2}$ within $)$ is sometimes also referred to as the cluster effect. A high intra-class correlation indicates that that the observations within groups are dependent or correlated, and that if one were to use traditional statistical techniques, the standard errors obtained will be underestimated. In this study, the 
intraclass correlation was moderate $(0.18)$. Therefore, the analysis should take into account the clustering effect of the data.

Another factor to consider would be to examine the cross-level interactions between establishment-level variables (in this case it is the establishment rule on condom use) and the intervention type. This contextual variable (establishment rule) had a moderating effect on the intervention, which would have been missed if one were to examine only individual-level effects. The fact that we found significant interaction effects on all three intervention groups indicates that establishment rule had a substantial impact on condom use. It is interesting to observe that twenty-four per cent of the variation lies between establishments, and $14 \%$ of the variation lies between cities.

\section{Limitations of the Study}

There are several limitations to this study. Our measures are mostly based on self-reports and are subject to errors in recall or social desirability bias. However, previous studies using these condom use measures have found no significant differences in social desirability among those reporting always or often using condoms compared with those reporting using condoms less frequently [35].

This study examined pre- and post results of the intervention using a three-level model using HLM. Currently, HLM software analyses are limited to three-level hierarchical models [36]. Future research can expand on this model to longitudinally examine pre-, post and follow-up measures using four-level hierarchical linear models that include the repeated measures across time. This would allow us examine the intervention effects across a longer time frame beyond 12 months. It would also enable us to examine the patterns of change across time since the intervention effect might not necessarily be linear but could have a plateau effect or even decrease after a longer period of time.

\section{Conclusion}

The results of this study stress the importance of the analysis at the individual level, establishment level, and community level, all of which affect individual behavior on condom use. Most intervention approaches target individuals, addressing personal issues of knowledge, attitudes and self-efficacy. However, these interventions do not take into account the organizational context in which change is taking place, and may miss opportunities to uncover some of the interesting findings at the other levels, which may also have an effect on the individual level. More recently, researchers have called for increased efforts in environmental and structural approaches for HIV prevention [6, 37]. These include organizational behavior changes and the establishment of policies regarding condom use in commercial sex establishments. Similarly, the issue of using multiple levels of analysis in HIV prevention science had been brought to the researchers' attention, calling for more efforts to 'widen the lens through which HIV/AIDS prevention is viewed' $[5,6]$.

The results in this study suggest that the work establishment is an important factor influencing condom use among GROs. In order for the intervention to be effective, organizational changes within the sex establishments need to be included in the intervention. These changes includes administering mandatory condom use rule in the establishments, training of managers in basic knowledge regarding the transmission and prevention of STIs, and encouraging employees to attend AIDS prevention training programs in the community.

Educational policy and activities carried out by managers also vary between establishments. A survey of the managers in the establishments shows that $81 \%$ of the managers meet regularly with the GROs, $75 \%$ promote AIDS awareness in the establishments, $72 \%$ encourage GROs to attend the social hygiene clinics, and 53\% mandate $100 \%$ condom use when having sex with clients [6].

In using multilevel hierarchical models as the method of analysis, the importance of targeting both individuals as well as contextual factors in the intervention was emphasized and taken into consideration. In this study, the effect of the combined peer and managerial intervention was found to be most effective, which suggested the need for the development of comprehensive educational policies in the commercial establishments, which not only target the GROs, but also the management of the sex establishments, and their policy on condom use.

Research in Thailand has demonstrated the value of combining interventions concurrently at the individual, establishment and community level. This study involves the dissemination of knowledge of safe sex practices among GROs through community outreach education programs and the government initiated policy of $100 \%$ condom use for preventing the spread of HIV infection, where the end result was significant increases in condom use among female sex workers and their male clients [28-30]. Clearly, the establishments and the communities where the GRO works exerts vital influence on condom use, thus the analysis of HIV/STI interventions involving this type of intervention should incorporate the analysis of effects both at the establishment and at the community level.

Acknowledgments We extend appreciation to co-investigators Drs. Teodora Tiglao, Sandra Tempongko and Jane Baltazar; site 
coordinators Dorcas Romen, Mildred Publico, Angie Casas and Lolipel Gella and to the research manager Daisy Mejilla. This research was supported by Grant R01-AI33845A from the National Institutes of Allergy and Infectious Diseases to Donald E. Morisky. Alfonso Ang was supported by the Robert Wood Johnson Foundation Network for Multicultural Research on Health and Healthcare.

Open Access This article is distributed under the terms of the Creative Commons Attribution Noncommercial License which permits any noncommercial use, distribution, and reproduction in any medium, provided the original author(s) and source are credited.

\section{References}

1. Flicker S, Savan B, Kolenda B, Mildenberger M. A snapshot of community-based research in Canada: Who? What? Why? How? Health Educ Res. 2008;23(1):106-14.

2. Minkler M. Community-based research partnerships: challenges and opportunities. J Urban Health. 2005;82(Suppl. 2):ii3-12.

3. Mosavel M, Simon C, van Stade D, Buchbinder M. Communitybased participatory research (CBPR) in South Africa: engaging multiple constituents to shape the research question. Soc Sci Med. 2005;61:2577-87.

4. Higgins DL, Metzler M. Implementing community-based participatory research centers in diverse urban settings. J Urban Health. 2001;78:488-94.

5. Msisha WM, Kapiga SH, Earls FJ, Subramanian SV. Place matters: multilevel investigation of HIV distribution in Tanzania. AIDS. 2008;22(6):741-8.

6. Morisky DE, Stein JA, Chiao C, Ksobiech K, Malow R. Impact of a social influence intervention on condom use and sexually transmitted infections among establishment-based female sex workers in the Philippines: a multilevel analysis. Health Psycho. 2006;25(5):595-603.

7. Chen J, Choe MK, Chen S, Zhang S. The effects of individualand community-level knowledge, beliefs, and fear on stigmatization of people living with HIV/AIDS in China. AIDS Care. 2007;9(5):666-73.

8. Morisky DE, Nguyen C, Ang A, Tiglao TV. HIV/AIDS prevention among the male population: results of a peer education program for taxicab and tricycle drivers in the Philippines. Health Educ Behav. 2005;32(1):57-68.

9. Amadora-Nolasco F, Alburo RE, Aguilar EJ, Trevathan WR. Knowledge and perception of risk for HIV and condom use among male injecting drug users in Cebu City, Philippines. Drug Alcohol Rev. 2002;21(2):137-43.

10. Fishbein M, Pequegnat W. Evaluating AIDS prevention interventions using behavioral and biological outcome measures. Sex Transm Dis. 2000;27:101-10.

11. Gabrysch S, Edwards T, Glynn JR, and Study Group on Heterogeneity of HIV Epidemics in African Cities. The role of context neighbourhood characteristics strongly influence HIV risk in young women in Ndola, Zambia. Trop Med Int Health 2008;13(2):162-70.

12. Beaudoin CE. HIV prevention in sub-Saharan Africa: a multilevel analysis of message frames and their social determinants. Health Promot Int. 2007;22(3):198-206.

13. Waldo CR, Coates TJ. Multiple levels of analysis and intervention in HIV prevention science: exemplars and directions for new research. AIDS. 2000;14(Suppl):S18-26.

14. Okulate GT, Jones OB, Olorunda MB. Condom use and other HIV risk issues among Nigerian soldiers: challenges for identifying peer educators. AIDS Care. 2008;20(8):911-6.

15. Choi KH, Hoff C, Gregorich SE, Grinstead O, Gomez C, Hussey $\mathrm{W}$. The efficacy of female condom skills training in HIV risk reduction among women: a randomized controlled trial. Am J Pub Health. 2008;98(10):1841-8.

16. Tucker JD, Chang SW, Tulsky JP. The catch 22 of condoms in US correctional facilities. BMC Public Health. 2007;21(7):296.

17. Aral SO. Sexually transmitted diseases: magnitude, determinants and consequences. Int J STD AIDS. 2001;12:211-5.

18. Latka M, Gollub E, French P, Stein Z. Male-condom and femalecondom use among women after counseling in a risk-reduction hierarchy for STD prevention. Sex Transm Dis. 2000;27:431-7.

19. Morisky DE, Peña M, Tiglao TV, Liu K. The impact of the work environment on condom use among female bar workers in the Philippines. Health Educ Behav. 2002;29(4):461-72.

20. O'Connell A, McCoach DB. Applications of hierarchical linear models for evaluations of health interventions: demystifying the methods and interpretations of multilevel models. Eval Health Prof. 2004;27(2):119-51.

21. Tinsman PD, Bullman S, Chen X, Burgdorf K, Herrell JM. Factors affecting client response to HIV outreach efforts. J Subst Abuse. 2001;13:201-14.

22. Raudenbush SW, Bryk AS. Hierarchical linear models: applications and data analysis methods. 2nd ed. Newbury Park, CA: Sage; 2002.

23. Goldstein HI. Multilevel statistical models. 3rd ed. London: Edward Arnold; 2003.

24. Snijders TAB, Bosker RJ. Multilevel analysis: An introduction to basic and advanced multilevel modeling. London: Sage; 1999.

25. Longford NT. Fisher scoring algorithm for variance component analysis of data with multilevel structure. In: Bock RD, editor. Multilevel analysis of educational data. Orlando: Academic Press; 1988. p. 297-310.

26. Sopheab H, Fylkesnes K, Lim Y, Godwin P. Community action for preventing HIV in Cambodia: evaluation of a 3-year project. Health Policy Plan. 2008;23(4):277-87.

27. Gorbach PM, Sopheab H, Chhorvann C, Weiss RE, Vun MC Changing behaviors and patterns among Cambodian sex workers: 1997-2003. JAIDS. 2006;42(2):242-7.

28. Ford K, Chamrathrithirong A. Sexual partners and condom use of migrant workers in Thailand. AIDS Behav. 2007;11(6):905-14.

29. Visrutaratna S, Lindan CP, Sirhorachai A, Mandel JS. "Superstar" and "Model Brothel": developing and evaluating a condom promotion program for sex establishments in Chiang Mai, Thailand. AIDS. 1995;9(Suppl):S69-75.

30. Ford N, Koetsawang S. A pragmatic intervention to promote condom use by female sex workers in Thailand. Bull World Health Organ. 1999;77:888-94.

31. Nelson KE, Eiumtrakul S, Celentano DD, Beyrer C, Galai N, Kawichai S, Khamboonruang C. HIV infection in young men in northern Thailand, 1991-1998: increasing role of injection drug use. J Acquir Immune Defic Syndr. 2002;29:62-8.

32. Tiglao T, Morisky DE, Tempongko S, Baltazar J, Detels R. A community participatory action research approach (P.A.R.) to HIV/ AIDS prevention among sex workers. Promot Educ. 1996;3(4):25-8.

33. Jemmott JB III, Jemmott LW, Spears H, Hewitt N, Cruz-Collins M. Self-efficacy, hedonistic expectancies, and condom-use intentions among inner-city Black adolescent women: a social cognitive approach to AIDS risk behavior. J Adolesc Health. 1992;13:512-9.

34. Royston P. Multiple imputation of missing values. Stata J. 2004;4:227-41.

35. Morisky DE, Ang A, Sneed CD. Validating the effects of social desirability on self-reported condom use behavior among commercial sex workers. AIDS Educ Prev. 2002;14(5):351-60.

36. Raudenbush SW, Bryk AS, Cheong YF, Congdon R. HLM 6: hierarchical linear and nonlinear modeling. Scientific Software International, 2004.

37. Merson MH. Early detection: the next steps. JAIDS. 2000;25(suppl):S157-9. 